\title{
Predicted no-effect concentrations for mercury species and ecological risk assessment for mercury pollution in aquatic environment
}

\author{
Meng $\mathrm{Du}^{1,2}$, Dongbin $\mathrm{Wei}^{1, *}$, Zhuowei $\mathrm{Tan}^{1}$, Aiwu $\mathrm{Lin}^{2}$, Yuguo $\mathrm{Du}^{1}$ \\ 1. State Key Laboratory of Environmental Chemistry and Ecotoxicology, Research Center for Eco-Environmental Sciences, Chinese Academy of \\ Sciences, Beijing 100085, China. E-mail: meng820701@163.com \\ 2. Water Quality Monitoring Center of Beijing Waterworks Group Company Limited, Beijing 100192, China
}

\section{A R T I C L E I N F O}

\section{Article history:}

Received 24 February 2014

Revised 3 June 2014

Accepted 4 June 2014

Available online 29 November 2014

Keywords:

Mercury

Species

Predicted no-effect concentration

Ecological risk assessment

\begin{abstract}
A B S T R A C T
Mercury (Hg) exists in different chemical forms presenting varied toxic potentials. It is necessary to explore an ecological risk assessment method for different mercury species in aquatic environment. The predicted no-effect concentrations (PNECs) for $\mathrm{Hg}$ (II) and methyl mercury (MeHg) in the aqueous phase, calculated using the species sensitivity distribution method and the assessment factor method, were 0.39 and $6.5 \times 10^{-3} \mu \mathrm{g} / \mathrm{L}$, respectively. The partition theory of $\mathrm{Hg}$ between sediment and aqueous phases was considered, along with PNECs for the aqueous phase to conduct an ecological risk assessment for $\mathrm{Hg}$ in the sediment phase. Two case studies, one in China and one in the Western Black Sea, were conducted using these PNECs. The toxicity of mercury is heavily dependent on their forms, and their potential ecological risk should be respectively evaluated on the basis of mercury species.
\end{abstract}

(c) 2014 The Research Center for Eco-Environmental Sciences, Chinese Academy of Sciences. Published by Elsevier B.V.

\section{Introduction}

Mercury (Hg) is a toxic element that exists in the environment and impacts human and ecosystem health even at extremely low concentrations. Both natural and anthropogenic sources are responsible for increasing the levels of $\mathrm{Hg}$ in aquatic environment. In the 1970s, Hg pollution appeared for the first time in the state of Michigan, USA (Taylor, 2000). The total Hg concentration in sea water in Vlora Bay of Albania was about $0.121 \mathrm{mg} / \mathrm{L}$ (Lodenius et al., 2004). In an 8-ha residential area in Southern Germany, there was a groundwater plume with a maximum $\mathrm{Hg}$ concentration of $230 \mu \mathrm{g} / \mathrm{L}$ (Bollen et al., 2008). A great deal of research on $\mathrm{Hg}$ pollution has also been conducted in China. For example, $\mathrm{Hg}$ concentration of $3.89 \mu \mathrm{g} / \mathrm{L}$ have been found in the Weisha River reach of the Songhua River, and average $\mathrm{Hg}$ concentrations of $1.61 \mu \mathrm{g} / \mathrm{L}$ have been found in water from the
Gedian area ( $\mathrm{Hu}, 2008)$. In addition, studies of $\mathrm{Hg}$ pollution in sediments should not be ignored due to the frequent transfer and transform. Bollen et al. (2008) found that a residential area was contaminated with up to $11,000 \mathrm{mg} / \mathrm{kg}$ of $\mathrm{Hg}$ in Southern Germany. Total Hg concentrations of $11.19-78.22 \mathrm{mg} / \mathrm{kg}$ have been found in sediments in the province of Liaoning (Hu, 2008). Some developing countries, such as Brazil, Indonesia, Laos, Sudan, Tanzania, and Zimbabwe, which are engaged in artisanal gold mining are also contaminated with $\mathrm{Hg}$; this is particularly true in northwest Tanzania, where the concentration of $\mathrm{Hg}$ in urban soils was $0.05-9.2 \mathrm{mg} / \mathrm{kg}$ (Taylor et al., 2005).

$\mathrm{Hg}$ pollution has attracted much attention because of the high toxicity of $\mathrm{Hg}$ and its increasingly widespread presence. It has been reported that low doses of $\mathrm{Hg}$ can damage different organ systems, like the nervous system, the motor system, the cardiovascular system, and the kidney system (Zahir et al.,

\footnotetext{
* Corresponding author. E-mail: weidb@rcees.ac.cn (Dongbin Wei).
} 
2005). A recent study showed that mercurial compounds would readily cross the placental barrier and the blood-brain barrier, damaging the developing brain (Christinal and Sumathi, 2013). In fact, $\mathrm{Hg}$ occurs as different chemical species, including inorganic (e.g., $\mathrm{Hg}(\mathrm{I})$ or $\mathrm{Hg}(\mathrm{II})$ ) and organic (e.g., methyl mercury (MeHg), ethyl mercury (EtHg), and phenyl mercury ( $\mathrm{PhHg})$ ). It has been proved that mercury with different forms exhibited quite different toxicities, but organic $\mathrm{Hg}$ compounds are more toxic than inorganic species (Leopold et al., 2010). Among them, $\mathrm{MeHg}$ is the most common but most toxic mercurial species in the environment (Mason and Fitzgerald, 1996). Because of the close relationship between toxicity and chemical form for $\mathrm{Hg}$ species, it is very hard to accurately represent the potential toxicity or biological availability using the total $\mathrm{Hg}$ concentration in water or sediment samples (Jain et al., 2007). Therefore, instead of total Hg, the concentrations of the different species of $\mathrm{Hg}$ in environmental samples should be respectively determined, which is important for accurately performing ecological risk assessment (ERA) on $\mathrm{Hg}$ pollution. The aim of this study was: (1) to obtain predicted no-effect concentrations (PNECs) for the predominant Hg species in aqueous environments by collecting and analyzing their toxicity data; and (2) to assess the ecological risk of different $\mathrm{Hg}$ species in case studies based on the computed risk thresholds of mercury species. The results of the present study may provide useful information for an accurate assessment of the potential risk of different species of $\mathrm{Hg}$ in the environment.

\section{Materials and methods}

\subsection{Toxicological data collection}

Hg toxicity data were collected from the US Environmental Protection Agency 'ECOTOX' database (http://cfpub.epa.gov/ ecotox/) and a number of publications, including research papers and government reports. The reliability, relevance, and adequacy of all the data that included acute and chronic lethal toxicity data and chronic reproductive toxicity data were then evaluated by standard methods (European Commission, 2003; Klimisch et al., 1997). Data were collected for at least 10 species at three trophic levels (e.g., algae, crustaceans, and fish). The means of several toxicity datasets were calculated for the species of interest collected from the same location at the same time, and a number of indices that express certain toxic characteristics, including mortality, growth parameters, biochemical parameters, and reproductive success, were selected as endpoints. For the screening of chronic toxicity data, the no observed effect concentration (NOEC) with the longest exposure time was selected when several eligible chronic toxicity data for the same species were available. When the NOEC of species was not available, NOEC was estimated to be equivalent to half of the lowest observed effect concentration (LOEC) value for the species (Balk et al., 1995).

\subsection{Calculating PNEC values for mercury in water phase (PNEC water $)$}

The predicted no-effect concentration (PNEC) is an important index in evaluating potential risk of toxic chemical. To protect most organisms in the environment, the species sensitivity distribution (SSD) curve and assessment factor (AF) method proposed by the European Union, which are commonly used for determining water quality criteria to calculate the predicted no-effect concentration (Wu et al., 2011a,b,c). PNEC is obtained on the basis of the NOEC. However, owing to the lack of NOEC available for many compounds, the NOECs used for ERA are extrapolated from acute toxicity data, such as the median lethal concentration (LC50) or the 50\% effective concentration (EC50).

\subsubsection{Species sensitivity distribution method}

The SSD method was first proposed by Kooijman (1987) and later improved by subsequent studies (Aldenberg and Slob, 1993; Newman et al., 2000; Posthuma et al., 2002; Wagner and Lokke, 1991). It is generally applied to circumstances in which there are at least 10 available toxicity data (Jin et al., 2009; Balk et al., 1995; Lei et al., 2009). In the SSD method, the curve for a pollutant is established based on available toxicological data for all species. The criterion level is then determined by finding the pollutant concentration on the curve that results in a predetermined noticeable effect in a certain percentage of the population. The criterion level, which is usually labeled $\mathrm{HC5}$, is the pollutant concentration that is hazardous to $5 \%$ of the species for which data are available (Van Straalen and Van Rijn, 1998). In general, the more data there is available, the higher the reliability of the assessment. The SSD method uses toxicological data for almost all species and considers the uncertainty resulting from heterogeneity between species. In the SSD method, data processing is critical. Specifically, the collected toxicological data should be checked first, and log-transformed when necessary. Then the data are sorted and the cumulative probability $\left(P_{c}\right)$ is calculated by Eq. (1):

$P_{\mathrm{c}}=i /(n+1)$

where, $i$ is the rank of a species in the data series and $n$ is the total number of species examined (Hall et al., 1998; Schuler et al., 2008). The SSD curve was constructed using the mean toxicity (or the logarithmic value) as the $x$-axis and the cumulative probability as the $y$-axis. The HC5 was determined by extrapolating the curve.

\subsubsection{Assessment factor method}

The assessment factor (AF) method that is applied in situations in which there are fewer toxicological data, generally no more than 10 datasets; it is used as a Supplementary method of the SSD method. It is widely used because of the simplicity of the operations involved and the less restrictive condition requirements. There was high variability in the data when less than 10 toxicity datasets were available, so the calculated effect endpoint (HC5) may have been unreliable; therefore, in such instances the AF method was used. The most important component of the AF method is the selection of a suitable assessment factor. Table 1 provides the guidelines for the selection of appropriate AF values given the amount and type of data available. The PNEC is calculated as the ratio of the minimum LC50 (EC50, or NOEC) value to the corresponding AF value.

\subsection{Calculating PNEC values for mercury in sediment phase (PNEC sed $)$}

The ERA of sediment contamination is similar to that of water contamination. The PNEC for each toxic pollutant in sediment 


\begin{tabular}{|c|c|c|}
\hline $\begin{array}{l}\text { Case } \\
\text { no. }\end{array}$ & Available toxicity data & $\mathrm{AF}$ \\
\hline 1 & $\begin{array}{l}\text { Acute LC50 or EC50 values available for } \\
\text { at least one species from three trophic } \\
\text { levels (fish, daphnia, and algae) }\end{array}$ & 1000 \\
\hline 2 & $\begin{array}{l}\text { Chronic NOEC values available for } \\
\text { one species (fish or daphnia) }\end{array}$ & 100 \\
\hline 3 & $\begin{array}{l}\text { Chronic NOEC values available for } \\
\text { two species from two trophic levels } \\
\text { (fish, daphnia, and/or algae) }\end{array}$ & 50 \\
\hline 4 & $\begin{array}{l}\text { Chronic NOEC values available for } \\
\text { three species from three trophic } \\
\text { levels (fish, daphnia, and algae) }\end{array}$ & 10 \\
\hline 5 & $\begin{array}{l}\text { Chronic NOEC values available for } \\
\text { three phyla and eight families } \\
\text { available using the SSD method }\end{array}$ & $1-5$ \\
\hline 6 & $\begin{array}{l}\text { Toxicity data from field observations } \\
\text { or ecological system simulation }\end{array}$ & $\begin{array}{l}\text { Depends on } \\
\text { the specific } \\
\text { circumstances }\end{array}$ \\
\hline \multicolumn{3}{|c|}{$\begin{array}{l}\text { LC50: median lethal concentration; EC50: } 50 \% \text { effective concentration; } \\
\text { NOEC: no observable effect concentration; SSD: species sensitivity } \\
\text { distribution. }\end{array}$} \\
\hline
\end{tabular}

should be calculated using the SSD or AF methods, depending on the ecological toxicity data available. However, for most of the toxic pollutants, the toxicity data in sediment were relatively scarce and properties (such as organic carbon content) of sediment in different areas varied widely, which makes risk assessment for sediments difficult. Fortunately, the concentration of a pollutant in sediment can be indirectly reflected by the concentration of the pollutant in pore water, using the equilibrium distribution model. Therefore, by means of the PNEC value of $\mathrm{Hg}$ in water and the concentration of a pollutant in pore water, the risk assessment of a pollutant in pore water could be performed. The concentration of a pollutant in pore water can be calculated by Eq. (2) (Zhao et al., 2010):

$C_{\text {porewater }}=C_{\text {sed }, i} / K_{\mathrm{oc}, i} \times F_{o c}$

where, $C_{\text {porewater }}(\mathrm{mg} / \mathrm{L})$ is the pollutant concentration in the pore water; $C_{\text {sed,i }}(\mathrm{mg} / \mathrm{kg})$ is the pollutant concentration in the sediment, $K_{\mathrm{oc}, \mathrm{i}}(\mathrm{L} / \mathrm{kg})$ is the equilibrium distribution coefficient (sediment/water) for the pollutant, and $F_{\text {oc }}(\%)$ is the organic carbon content in the sediment.

\subsection{Risk assessment}

The most feasible method for the characterization of the potential risk of a toxic pollutant is to use the index risk quotient (RQ), which is calculated by Eq. (3). If $R Q \geq 1$, the risk posed by the pollutant is high; if $R Q<1$, the risk is low (Naftz et al., 2008).

$$
\mathrm{RQ}=C_{\mathrm{e}} / \text { PNEC }
$$

where, $C_{e}(\mu \mathrm{g} / \mathrm{L})$ is the environmental concentration, PNEC $(\mu \mathrm{g} / \mathrm{L})$ is the predicted no-effect concentration.

\subsection{Sample collection and detection}

\subsubsection{Sample collection and preparation}

In December 2008 (the dry season) and July 2009 (the wet season), surface water samples (from 0 to $20 \mathrm{~cm}$ ) and surface sediment samples (from 0 to $20 \mathrm{~cm}$ ) were collected from seven sites (P-A, P-B, P-C, P-D, P-E, P-F, P-G) in the Pearl River Delta. In the surrounding of this area, there are a lot of industrial factories, such as textile industry, electronics industry, mining and so on, which may discharge mercury into the environment. Therefore, this area was targeted and the mercury distribution in the region was analyzed. The sampling sites were shown in the Supplementary materials (Appendix Fig. S1). The $\mathrm{pH}$ of the water samples was adjusted to 2 with $2 \mathrm{~mol} / \mathrm{L} \mathrm{HNO}_{3}$ and the samples were filtered using 0.70- $\mu \mathrm{m}$ filters (GF/F Waterman, Maidstone, UK). The sediment samples were collected with a stainless steel sediment sampler and sodium azide was added to the samples to prevent changes in the chemical speciation of $\mathrm{Hg}$ that may be caused by the activity of microorganisms. Then the sediment samples were transferred to acid-washed dark-colored polyethylene bags and transported to the laboratory within $4 \mathrm{hr}$. The sediment samples were freeze-dried (FD-1, Shanghai Joyn Electronic, Shanghai, China), slightly crushed, passed through a 60 mesh sieve, and stored at $4^{\circ} \mathrm{C}$ in aluminum foil to avoid sunlight exposure until analysis.

\subsubsection{Sample detection}

The concentrations of different Hg species in water and sediment samples were detected by liquid chromatography-hydride generation-atomic fluorescence spectrometry (abbreviated as LCHG-AFS, Beijing Titan Instruments, Beijing, China). The standards of $\mathrm{Hg}(\mathrm{II}), \mathrm{MeHg}$, and $\mathrm{EtHg}$ were purchased from Sigma-Aldrich (St Louis, MO, USA). Detailed operational parameters of instrumental analysis are shown in Appendix Table S1.

The water samples were concentrated by 10 times, then analyzed by LC-HG-AFS after they were filtered through a $0.22-\mu \mathrm{m}$ filter. The $0.2000 \mathrm{~g}$ of sediment sample was placed in a $50 \mathrm{~mL}$ conical flask, then $2 \mathrm{~mL}$ of extracted liquid was added, mixed for $5 \mathrm{~min}$ and centrifuged, then the supernatant was collected. Extracted liquid ( $2 \mathrm{~mL}$ ) was added to the sample again and the previous operation was repeated and all of the supernatant was merged. The supernatant was filtered through a $0.22-\mu \mathrm{m}$ filter, then purified by passage through a $\mathrm{C}_{18}$ column, and was then eluted using $4 \mathrm{~mL}$ of the mobile phase solution. Finally, the supernatant was diluted with water to a volume of $10 \mathrm{~mL}$ and filtered through a $0.22-\mu \mathrm{m}$ filter before it was analyzed by LC-HG-AFS.

\subsubsection{Quality assurance}

Milli-Q (Millipore, Bedford, MA, USA) water was used to prepare all the extraction solutions. All of the glassware used for sampling and chemical analysis were soaked in nitric acid for at least $24 \mathrm{hr}$ and were washed with ultrapure water before use. Samples were analyzed in triplicate and the results were considered valid only when the correlation coefficients of the standard curve were greater than 0.995. Meanwhile, field blanks and lab blanks were used to ensure that experimental data obtained was accurate. The chromatogram of $\mathrm{Hg}(\mathrm{II}), \mathrm{MeHg}$, and $\mathrm{EtHg}$ is shown in Appendix Fig. S2. The calibration curves for three species and 
corresponding correlation coefficients $(R)$ are shown in Appendix Table S2. Standard addition experiments showed that the average recoveries of $\mathrm{Hg}(\mathrm{II}), \mathrm{MeHg}$, and $\mathrm{EtHg}$ were $79 \%-108 \%$. The minimum instrumental detection limits for $\mathrm{Hg}(\mathrm{II}), \mathrm{MeHg}$, and EtHg were $0.04,0.04$, and $0.05 \mu \mathrm{g} / \mathrm{L}$, respectively. The relative standard deviations for the analyses were lower than $5 \%$, which means that the results reached the required precision.

\section{Results and discussion}

\subsection{Calculation of PNECs for different mercury species in water}

2.1.1. PNEC calculation for $\mathrm{Hg}$ (II) in water using the SSD method A total of 52 toxicity data tested with 15 species for $\mathrm{Hg}$ (II) (CAS No. 7487947) passed reliability screening. Among them, 17\% were for vertebrates, $69 \%$ for invertebrates, and $14 \%$ for plants. With these toxicity data, the SSD curves for $\mathrm{Hg}$ (II) were established using a log-logistic model (Fig. 1). The determination coefficient $\left(R^{2}\right)$ was 0.95 , the $F$ test value was 1491.64 , and the $p$ value was less than 0.001 . The PNEC value of $\mathrm{Hg}$ (II) was $0.39 \mu \mathrm{g} / \mathrm{L}$. This value was comparable to the proposed chronic water quality criteria $(0.467 \mu \mathrm{g} / \mathrm{L})$ for inorganic mercury reported by Zhang et al. (2012). Rodrigues et al. (2013) also reported that the PNEC of $\mathrm{Hg}$ (II) varied between 0.636 and $3.18 \mu \mathrm{g} / \mathrm{L}$, suggesting relatively low risk to algae, plants, crustaceans, or insects in most freshwater ecosystems.

\subsubsection{PNEC calculation for $\mathrm{MeHg}$ in water using AF method}

Since less than 10 acute and chronic toxicity data for $\mathrm{MeHg}$ (CAS No. 22967926) were collected, the AF method was used to calculate the PNEC value. Two chronic NOEC values of $\mathrm{MeHg}$ were available for two species of crustaceans and fish, so the $\mathrm{AF}$ value was selected as 50 according to the choosing principle in Table 1. The minimal NOEC result is from Hyalella azteca, for which the NOEC value is $0.325 \mu \mathrm{g} / \mathrm{L}$. The PNEC value for $\mathrm{MeHg}$ was therefore $6.5 \times 10^{-3} \mu \mathrm{g} / \mathrm{L}$. It has been reported that $\mathrm{MeHg}$ is $10-100$ times more toxic than inorganic $\mathrm{Hg}$, and

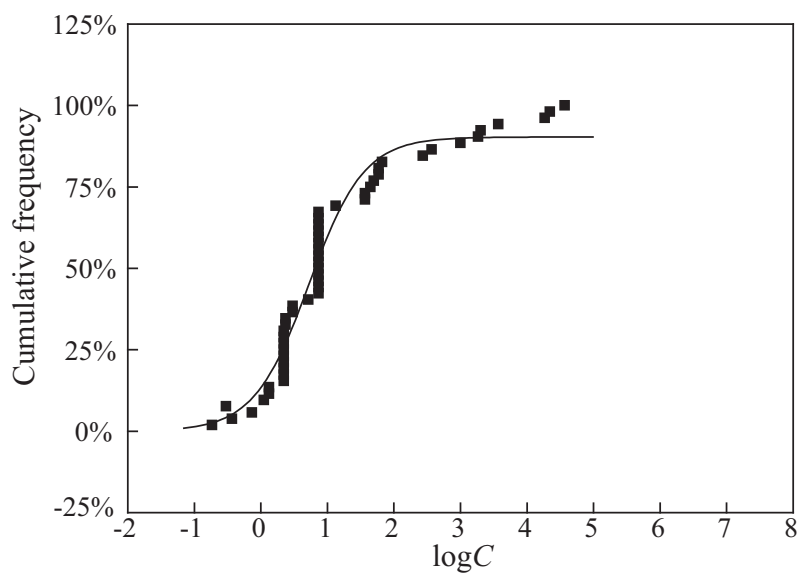

Fig. 1 - Species sensitivity distribution (SSD) curves of $\mathrm{Hg}$ (II). LogC represents the logarithm of the no observed effect concentrations (NOECs) of $\mathrm{Hg}$ (II). the findings of our study are in agreement with this (National Academy of Science, 1978; Horvat et al., 2003). Studies should therefore be focused on the strong toxicity of $\mathrm{MeHg}$ and the ecological risk associated with $\mathrm{MeHg}$. This indicates that the importance of analyzing different $\mathrm{Hg}$ species when the toxicity of $\mathrm{Hg}$ is being measured; the relative contributions of $\mathrm{Hg}$ (II) and $\mathrm{MeHg}$ to the total $\mathrm{Hg}$ concentration should be taken into account to obtain accurate toxicity information.

Much research conducted on $\mathrm{Hg}$ pollution is based on the concentration of total $\mathrm{Hg}$ and does not consider the variation in toxicity of different $\mathrm{Hg}$ species. The limit values of Chinese environmental quality standards for surface water (GB 3838-2002, Class III) and Chinese environmental quality standard for soils (GB 15618-1995 Class I) are $0.0001 \mathrm{mg} / \mathrm{L}$ and $0.15 \mathrm{mg} / \mathrm{kg}$, which are also for the total $\mathrm{Hg}$ concentration; different values are not indicated for different $\mathrm{Hg}$ species. Because total $\mathrm{Hg}$ toxicity will depend directly on the relative concentrations of the different $\mathrm{Hg}$ species present, limits should be set for different $\mathrm{Hg}$ species in the Chinese environmental quality standards.

\subsection{Risk assessment of mercury pollution}

\subsubsection{Case study in the Pearl River Delta}

The $\mathrm{Hg}(\mathrm{II})$ and $\mathrm{MeHg}$ concentrations in the samples taken from the seven sites in the Pearl River Delta in the dry season and wet season are shown in Table 2. MeHg was not detected in water samples in the Pearl River Delta. The concentrations of $\mathrm{Hg}$ (II) in water samples in wet season $(0.02-0.08 \mu \mathrm{g} / \mathrm{L})$ were much higher than those in dry season $(0.01-0.05 \mu \mathrm{g} / \mathrm{L})$. The reason may be the rich rainfall in summer, strong atmospheric wet deposition and surface runoff taking much mercury into river water. The concentration ranges of $\mathrm{Hg}$ (II) in sediments in the dry season and the wet season were 0.020.16 and $0.01-0.22 \mathrm{mg} / \mathrm{kg}$, respectively. The corresponding concentration ranges of $\mathrm{MeHg}$ in sediments were ND-0.01 and ND-0.02 mg/kg, respectively. Considering the Chinese environmental quality standard for soils (GB 15618-1995, Class I) is $0.15 \mathrm{mg} / \mathrm{kg}$, the pollution of $\mathrm{Hg}$ exists in sediments in the Pearl River Delta. The species PhHg was not detected in any of the 14 samples. The $\mathrm{Hg}$ concentrations in the pore water $\left(C_{\text {porewater }}\right)$ were calculated from the concentrations in the sediment samples for indirectly assessing the ecological risk from $\mathrm{Hg}$, and the results are shown in Table 3 . The results demonstrate that $\mathrm{Hg}$ (II) was the dominant species in sediment.

Using the environmental concentrations of different $\mathrm{Hg}$ species and the corresponding PNEC values, the RQ values of different $\mathrm{Hg}$ species for the water samples collected from the Pearl River Delta were calculated and listed in Table 4. The results showed that all the RQ values of water samples were less than 1, indicating that the potential ecological risk from $\mathrm{Hg}$ (II) and $\mathrm{MeHg}$ in water were low in the study area. With the PNECs obtained in this study, the ecological risk from different $\mathrm{Hg}$ species in water all over the world could be evaluated as well. The following are examples of Hg concentrations that have been reported in previous studies and RQ values calculated. In Great Salt Lake, UT, USA, the $\mathrm{MeHg}$ concentration in the monimolimnion was 10-40 ng/L and the corresponding RQ value was 1.54-6.15 (Naftz et al., 2008). In 
Table 2 - Hg(II) and methyl mercury (MeHg) concentrations in water and sediment samples from seven sites in the Pearl River Delta in the dry season and the wet season.

\begin{tabular}{|c|c|c|c|c|c|c|c|c|}
\hline \multirow[t]{3}{*}{ Sampling site } & \multicolumn{4}{|c|}{ Dry season } & \multicolumn{4}{|c|}{ Wet season } \\
\hline & \multicolumn{2}{|c|}{ Water $(\mu \mathrm{g} / \mathrm{L})$} & \multicolumn{2}{|c|}{ Sediment (mg/kg) } & \multicolumn{2}{|c|}{ Water $(\mu \mathrm{g} / \mathrm{L})$} & \multicolumn{2}{|c|}{ Sediment (mg/kg) } \\
\hline & $\mathrm{Hg}(\mathrm{II})$ & $\mathrm{MeHg}$ & $\mathrm{Hg}(\mathrm{II})$ & $\mathrm{MeHg}$ & $\mathrm{Hg}(\mathrm{II})$ & $\mathrm{MeHg}$ & $\mathrm{Hg}(\mathrm{II})$ & $\mathrm{MeHg}$ \\
\hline P-A & 0.03 & ND & 0.10 & ND & 0.04 & ND & 0.22 & ND \\
\hline P-B & 0.01 & ND & 0.07 & ND & 0.08 & ND & 0.13 & ND \\
\hline P-C & 0.05 & ND & 0.16 & ND & 0.08 & ND & 0.08 & 0.01 \\
\hline P-D & 0.02 & ND & 0.02 & ND & 0.06 & ND & 0.13 & ND \\
\hline P-E & 0.02 & ND & 0.02 & ND & 0.02 & ND & 0.04 & 0.02 \\
\hline P-F & 0.02 & ND & 0.05 & 0.01 & 0.06 & ND & 0.03 & ND \\
\hline P-G & 0.03 & ND & 0.08 & ND & 0.06 & ND & 0.01 & ND \\
\hline Range & $0.01-0.05$ & ND & $0.02-0.16$ & ND-0.01 & $0.02-0.08$ & ND & $0.01-0.22$ & ND-0.02 \\
\hline Total Hg & $0.01-0.05$ & & $0.02-0.16$ & & $0.02-0.08$ & & $0.01-0.22$ & \\
\hline
\end{tabular}

the Huangdao River in the province of Guizhou, the $\mathrm{Hg}$ (II) concentration was 2.1-390 ng/L, the MeHg concentration was 0.31-0.43 ng/L, and the corresponding RQ values were $0.005-1$ and less than 1, respectively (Qiu et al., 2009). In water from Maryland reservoirs, the $\mathrm{MeHg}$ concentration was $0.007-$ $0.493 \mathrm{ng} / \mathrm{L}$ and the corresponding RQ value was less than 1 (Sveinsdottir and Mason, 2005). The concentration range of $\mathrm{MeHg}$ in Lake Moreno water was $0.26-0.68 \mathrm{ng} / \mathrm{L}$ and the corresponding $\mathrm{RQ}$ value was less than 1 (Arribere et al., 2010). It can be concluded that the potential ecological risk from $\mathrm{Hg}$ (II) and $\mathrm{MeHg}$ in water is higher in other aquatic systems around the world than in the Pearl River Delta. In addition, although the toxicity of $\mathrm{MeHg}$ is higher than $\mathrm{Hg}(\mathrm{II})$, the ecological risk from $\mathrm{MeHg}$ was not high because of the low concentration in water phase.

Sediment can act as a major "sink" of chemical contaminants, Hg "saved" in the sediment bank can be released into water again, and the aqueous phase would then be subject to secondary pollution. The RQ values (Table 4) for different $\mathrm{Hg}$ species in sediment samples can be indirectly calculated from their concentrations in pore water and the corresponding PNEC values.

Table 3-Hg(II) and MeHg concentrations in pore water $\left(C_{\text {porewater }}\right)$ at the seven sampling points in the Pearl River Delta in the dry season and the wet season.

\begin{tabular}{|c|c|c|c|c|c|c|}
\hline \multirow{2}{*}{$\begin{array}{l}\text { Sampling } \\
\text { site }\end{array}$} & \multicolumn{3}{|c|}{ Dry season } & \multicolumn{3}{|c|}{ Wet season } \\
\hline & $\begin{array}{l}F_{\text {oc }} \\
(\%)\end{array}$ & $\begin{array}{l}\mathrm{Hg}(\mathrm{II}) \\
(\mu \mathrm{g} / \mathrm{L})\end{array}$ & $\begin{array}{l}\mathrm{MeHg} \\
(\mu \mathrm{g} / \mathrm{L})\end{array}$ & $\begin{array}{l}F_{o c} \\
(\%)\end{array}$ & $\begin{array}{l}\mathrm{Hg}(\mathrm{II}) \\
(\mu \mathrm{g} / \mathrm{L})\end{array}$ & $\begin{array}{l}\mathrm{MeHg} \\
(\mu \mathrm{g} / \mathrm{L})\end{array}$ \\
\hline P-A & 5.4 & 6.58 & ND & 1.3 & 3.49 & ND \\
\hline P-B & 1.5 & 1.28 & ND & 4.4 & 6.98 & ND \\
\hline P-C & 2.1 & 4.09 & ND & 2.0 & 1.95 & 0.24 \\
\hline P-D & 0.4 & 0.10 & ND & 2.1 & 3.33 & ND \\
\hline P-E & 0.6 & 0.14 & ND & 0.8 & 0.39 & 0.20 \\
\hline P-F & 0.2 & 0.12 & $2.44 \times 10^{-2}$ & 1.1 & 0.40 & ND \\
\hline P-G & 5.2 & 5.07 & ND & 1.4 & 0.17 & ND \\
\hline Range & - & ND-6.58 & ND-2.44 $\times 10^{-2}$ & - & ND-6.98 & ND-0.24 \\
\hline
\end{tabular}

Equilibrium distribution coefficient: $0.82 \mathrm{~L} / \mathrm{kg}$ (Lindstrom, 2001). ND: not detected.

$F_{\text {oc: }}$ organic carbon content (\%) in sediment samples.
At site P-A to site P-C, and P-G, there was a high risk from $\mathrm{Hg}$ (II) in the dry season, and at site P-A to site P-F there was a high risk from $\mathrm{Hg}(\mathrm{II})$ in the wet season. At site P-F in dry season, site P-C and site $\mathrm{P}-\mathrm{E}$ in the wet season, there was a high risk from $\mathrm{MeHg}$ in sediments of the Pearl River Delta; the risk was most apparent for sites P-C and P-E in the wet season, at which the RQ values were 36.92 and 30.77, respectively. Within the studied area, much industrial factories, such as mining, textile industry developed rapidly, coupled with the domestic wastes and medical wastes, which would increase the concentration and the ecological risk of mercury in the study area. Because of the high toxicity of $\mathrm{MeHg}$, some studies have been conducted to determine the concentrations of MeHg in sediments. In Vembanadu Lake, the concentration range of $\mathrm{MeHg}$ was $0.27-37.40 \mathrm{mg} / \mathrm{kg}$ (Mohan et al., 2014). Ding et al. (2004) reported that the concentration of $\mathrm{MeHg}$ in sediment samples from the province of Guizhou, China, was $0.19-20.00 \mathrm{mg} / \mathrm{kg}$. In areas of the upper Songhua River, the concentration of $\mathrm{MeHg}$ was $0.04-0.45 \mathrm{mg} / \mathrm{kg}$ (Wang et al., 2005). In sediment samples around compact fluorescent lamp factories in the province of Zhejiang, China, the concentration of MeHg was 0.03-1.02 mg/kg (Shao et al., 2012). Because specific $F_{\text {oc }}$ values were not available for these studies, we were unable to obtain the RQ values. Considering the high $\mathrm{MeHg}$ concentrations of samples from the province of Guizhou and around compact fluorescent lamp factories in Zhejiang, the ecological risks of MeHg maybe much higher than it is in the Pearl River Delta.

Furthermore, it is well known that the chemical forms of mercury can be converted biotically and abiotically. Therefore, in order to evaluate the total risk of mercury at each sampling point, all the RQ values of $\mathrm{Hg}$ (II) and MeHg in both water and sediment phases at the same site were summed up (Table 4). The results showed that all of $7 \Sigma R Q$ values at sampling sites in wet season were much higher than in dry season. Meanwhile, the ecological risk of mercury in water was low, while it was high in most of the sediment samples. Considering that mercury could release from sediments to water again, mercury pollution in sediment could not be ignored. Especially, there are many mine engineering and spinneries around these sampling sites within the Pearl River Delta, more and more mercury would be discharged with the development of industry and city. It would be imperative to take 
Table 4 - Risk quotients (RQs) of Hg(II) and MeHg at the seven sampling points in the Pearl River Delta in the dry season and the wet season.

\begin{tabular}{|c|c|c|c|c|c|c|c|c|c|c|}
\hline \multirow[t]{3}{*}{ Sampling site } & \multicolumn{5}{|c|}{ Dry season } & \multicolumn{5}{|c|}{ Wet season } \\
\hline & \multicolumn{2}{|c|}{ RQ in water } & \multicolumn{2}{|c|}{ RQ in sediment } & \multirow[t]{2}{*}{$\Sigma R Q$} & \multicolumn{2}{|c|}{ RQ in water } & \multicolumn{2}{|c|}{ RQ in sediment } & \multirow[t]{2}{*}{$\Sigma \mathrm{RQ}$} \\
\hline & $\mathrm{Hg}(\mathrm{II})$ & $\mathrm{MeHg}$ & $\mathrm{Hg}(\mathrm{II})$ & $\mathrm{MeHg}$ & & $\mathrm{Hg}(\mathrm{II})$ & $\mathrm{MeHg}$ & $\mathrm{Hg}(\mathrm{II})$ & $\mathrm{MeHg}$ & \\
\hline P-A & $<1$ & $<1$ & 16.88 & $<1$ & 16.88 & $<1$ & $<1$ & 8.95 & $<1$ & 8.95 \\
\hline P-B & $<1$ & $<1$ & 3.28 & $<1$ & 3.28 & $<1$ & $<1$ & 17.89 & $<1$ & 17.89 \\
\hline P-C & $<1$ & $<1$ & 10.51 & $<1$ & 10.51 & $<1$ & $<1$ & 5.00 & 36.92 & 41.92 \\
\hline P-D & $<1$ & $<1$ & $<1$ & $<1$ & $<1$ & $<1$ & $<1$ & 8.54 & $<1$ & 8.54 \\
\hline P-E & $<1$ & $<1$ & $<1$ & $<1$ & $<1$ & $<1$ & $<1$ & 1.00 & 30.77 & 31.77 \\
\hline P-F & $<1$ & $<1$ & $<1$ & 3.75 & 3.75 & $<1$ & $<1$ & 1.03 & $<1$ & 1.03 \\
\hline P-G & $<1$ & $<1$ & 13.01 & $<1$ & 13.01 & $<1$ & $<1$ & $<1$ & $<1$ & $<1$ \\
\hline
\end{tabular}

some effective measures to control mercury pollution in the Pearl River Delta.

\subsubsection{Case study in the Western Black Sea}

Lamborg et al. (2008) reported the distribution of $\mathrm{Hg}$ (II) and $\mathrm{MeHg}$ in the Western Black Sea in March/April of 2005. The water column samples were collected from eight sites (CS1CS4, and WG1-WG4) in a Western Gyre (WG) site with a water depth slightly greater than $2000 \mathrm{~m}$, and a more coastal site (CS) with a water depth of ca. $300 \mathrm{~m}$. As shown in Table 5, for each species of $\mathrm{Hg}(\mathrm{Hg}$ (II) and $\mathrm{MeHg}$ ), the concentrations in the water samples from the different sites of Western Black Sea did not show obvious difference. But the concentrations of them were 100 times lower than those from the Pearl River Delta. With the PNEC values of $\mathrm{Hg}$ (II) and $\mathrm{MeHg}$ calculated in this study, the RQs of $\mathrm{Hg}(\mathrm{II})$ and $\mathrm{MeHg}$ were calculated for the water samples and shown in Table 5. Accordingly, it could be concluded that the ecological risks from $\mathrm{Hg}$ (II) and $\mathrm{MeHg}$ in sea waters in the Western Black Sea were low.

\section{Conclusions}

$\mathrm{Hg}$ exists in different forms in the environment, and $\mathrm{Hg}$ toxicity is dependent on its chemical forms. To accurately evaluate the potential ecological risk from $\mathrm{Hg}$, its different species should be considered respectively. The PNECs of $\mathrm{Hg}$ (II) and $\mathrm{MeHg}$ were 0.39 and $6.5 \times 10^{-3} \mu \mathrm{g} / \mathrm{L}$, which were calculated by the SSD method and the AF method, respectively. The water and sediment samples were collected from the Pearl

Table 5 - Concentrations and risk quotients (RQs) of $\mathrm{Hg}$ (II) and $\mathrm{MeHg}$ in water samples from the Western Black Sea.

\begin{tabular}{lcccccc}
\multirow{2}{*}{$\begin{array}{c}\text { Sampling } \\
\text { site }\end{array}$} & \multicolumn{3}{c}{ Concentration $(\mu \mathrm{g} / \mathrm{L})$} & & \multicolumn{2}{c}{$\mathrm{RQ}$} \\
\cline { 2 - 4 } \cline { 6 - 7 } \cline { 6 - 7 } & Total Hg & $\mathrm{Hg}(\mathrm{II})$ & $\mathrm{MeHg}$ & & $\mathrm{Hg}(\mathrm{II})$ & $\mathrm{MeHg}$ \\
\hline CS-1 & $3.61 \times 10^{-4}$ & $8.36 \times 10^{-5}$ & $6.92 \times 10^{-6}$ & & $<1$ & $<1$ \\
CS-2 & $2.09 \times 10^{-3}$ & $7.18 \times 10^{-5}$ & $1.82 \times 10^{-5}$ & & $<1$ & $<1$ \\
CS-3 & $3.41 \times 10^{-4}$ & $1.79 \times 10^{-4}$ & $2.44 \times 10^{-5}$ & & $<1$ & $<1$ \\
CS-4 & $1.52 \times 10^{-3}$ & $1.05 \times 10^{-4}$ & $2.41 \times 10^{-4}$ & & $<1$ & $<1$ \\
WG-1 & $6.02 \times 10^{-4}$ & $6.56 \times 10^{-5}$ & $2.24 \times 10^{-5}$ & & $<1$ & $<1$ \\
WG-2 & $5.42 \times 10^{-4}$ & $1.06 \times 10^{-4}$ & $2.49 \times 10^{-5}$ & & $<1$ & $<1$ \\
WG-3 & $4.61 \times 10^{-4}$ & $6.22 \times 10^{-5}$ & $1.08 \times 10^{-5}$ & & $<1$ & $<1$ \\
WG-4 & $7.22 \times 10^{-4}$ & $6.68 \times 10^{-5}$ & $5.67 \times 10^{-5}$ & & $<1$ & $<1$ \\
\hline
\end{tabular}

River Delta, China. The concentrations of different Hg species were determined, and their associated ecological risks of $\mathrm{Hg}$ (II) and $\mathrm{MeHg}$ in this area were assessed on the basis of the obtained PNECs of $\mathrm{Hg}$ (II) and $\mathrm{MeHg}$. The results showed that the ecological risks of $\mathrm{Hg}$ (II) and $\mathrm{MeHg}$ were high at some sample points in the Pearl River Delta. In addition, the ecological risk associated with different $\mathrm{Hg}$ species in sea waters in the Western Black Sea was low for both $\mathrm{Hg}$ (II) and $\mathrm{MeHg}$. We anticipate that this study may provide a method for accurately evaluating the potential risk of $\mathrm{Hg}$ contamination in environmental matrices by considering the respective contribution of different $\mathrm{Hg}$ species.

\section{Acknowledgments}

This work was financially supported in partial by National Key Technologies R\&D Program of China (Research \& Development on Suitable Key Technologies of the Village Environmental Monitoring, No. 2012BAJ24B01).

\section{Appendix A. Supplementary data}

Supplementary data associated with this article can be found in online version at http://dx.doi.org/10.1016/j.jes.2014.06.042.

\section{R E F E R E N C E S}

Aldenberg, T., Slob, W., 1993. Confidence limits for hazardous concentrations based on logistically distributed NOEC toxicity data. Ecotoxicol. Environ. Saf. 25 (1), 48-63.

Arribere, M., Dieguez, M.C., Guevara, S.R., Queimalinos, C.P., Fajon, V., Reissig, M., et al., 2010. Mercury in an ultraoligotrophic North Patagonian Andean lake (Argentina): concentration patterns in different components of the water column. J. Environ. Sci. 22 (8), 1171-1178.

Balk, F., Okkerman, P.C., Dogger, J.W., 1995. Guidance Document for Aquatic Effects Assessment. Organization for Economic Cooperation and Development, Paris, France pp. 22-28.

Bollen, A., Wenke, A., Biester, H., 2008. Mercury speciation analyses in $\mathrm{HgCl}_{2}$-contaminated soils and groundwater-implications for risk assessment and remediation strategies. Water Res. 42, 91-100. 
Christinal, J., Sumathi, T., 2013. Effect of Bacopa monniera extract on methylmercury-induced behavioral and histopathological changes in rats. Biol. Trace Elem. Res. 155 (1), 56-64.

Ding, Z.H., Wang, W.H., Qu, L.Y., Tang, Q.H., Liu, C.E., Cheng, J.P., et al., 2004. Mercury pollution and its ecosystem effects in Wanshan mercury miner area Guizhou. Environ. Sci. 25 (2), 111-114.

European Commission, 2003. Technical guidance document on risk assessment. Part II: environmental risk assessment. Commission Regulation (EC) No 1488/94 on Risk Assessment for Existing Substances. European Chemical Bureau, Luxemburg.

Hall, L.W., Scott, M.C., Killen, W.D., 1998. Ecological risk assessment of copper and cadmium in surface waters of Chesapeake Bay watershed. Environ. Toxicol. Chem. 17 (6), 1172-1189.

Horvat, M., Nolde, N., Fajon, V., Jereb, V., Logar, M., Lojen, S., et al., 2003. Total mercury, methylmercury and selenium in mercury polluted areas in the province Guizhou China. Sci. Total Environ. 304 (1-3), 231-256.

$\mathrm{Hu}$, Y.H., 2008. Review of mercury pollution distribution status research at home and abroad. Environ. Prot. Sci. 34 (1), 38-41.

Jain, C.K., Malik, D.S., Yadav, R., 2007. Metal fractionation study on bed sediments of Lake Nainital, Uttaranchal, India. Environ. Monit. Assess. 130 (1-3), 129-139.

Jin, X.W., Lei, B.L., Xu, Y.P., Zha, J.M., Wang, Z.J., 2009. Methodologies for deriving water quality criteria to protect aquatic life (ALC) and proposal for development of ALC in China: a review. Australas. J. Ecotoxicol. 4 (5), 609-616.

Klimisch, H.J., Andreae, M., Tillmann, U., 1997. A systematic approach for evaluating the quality of experimental toxicological and ecotoxicological data. Regul. Toxicol. Pharmacol. 25 (1), 1-5.

Kooijman, S.A.L.M., 1987. A safety factor for $\mathrm{LC}_{50}$ values allowing for differences in sensitivity among species. Water Res. 21 (3), 269-276.

Lamborg, C.H., Yigiterhan, O., Fitzgerald, W.F., Balcom, P.H., Hammerschmidt, C.R., Murray, J., 2008. Vertical distribution of mercury species at two sites in the Western Black Sea. Mar. Chem. 111 (1-2), 77-89.

Lei, B.L., Huang, S.B., Wang, Z.J., 2009. Theories and methods of ecological risk assessment. Prog. Chem. 21 (2-3), 350-358.

Leopold, K., Foulkes, M., Worsfold, P., 2010. Methods for the determination and speciation of mercury in natural waters-a review. Anal. Chim. Acta. 663 (2), 127-138.

Lindstrom, M., 2001. Distribution of particulate and reactive mercury in surface waters of Swedish forest lakes-an empirically based predictive model. Ecol. Model. 136 (1), 81-93.

Lodenius, M., Nuorteva, P., Nuorteva, S.L., 2004. Uptake of mercury by terrestrial plants-observations in Finland and Slovenia in the years 1979-1981. Mater. Geoenviron. 51 (2), 1181-1184.

Mason, R.P., Fitzgerald, W.F., 1996. The global mercury cycle: oceanic and anthropogenic aspects. In: Baeyens, W., Ebinghaus, R. (Eds.), Global and Regional Mercury Cycles: Sources. Kluwer Academic Publishers, Dordrecht, Fluxes and Mass Balances, p. 85.

Mohan, M., Chandran, M.S.S., Jayasooryan, K.K., Ramasamy, E.V., 2014. Mercury in the sediments of Vembanad Lake, western coast of India. Environ. Monit. Assess. 186, 3321-3336.

Naftz, D., Angeroth, C., Kenney, T., Waddell, B., Darnall, N., Silva, S., et al., 2008. Anthropogenic influences on the input and biogeochemical cycling of nutrients and mercury in Great Salt Lake, Utah USA. Appl. Geochem. 23 (6), 1731-1744.

National Academy of Science, 1978. An Assessment of Mercury in the Environment. National Research Council, Washington, DC.

Newman, M.C., Ownby, D.R., Mezin, L.C.A., Powell, D.C., Christensen, T.R.L., Lerberg, S.B., et al., 2000. Applying species-sensitivity distributions in ecological risk assessment: assumptions of distribution type and sufficient numbers of species. Environ. Toxicol. Chem. 19 (2), 508-515.

Posthuma, L., Traas, T.P., Suter II, G.W., 2002. General introduction to species sensitivity distributions. In: Posthuma, L., Suter II, G.W., Traas, T.P. (Eds.), Species Sensitivity Distributions in Ecotoxicology. CRC Press LLC, Boca Raton, pp. 3-9.

Qiu, G., Feng, X.B., Wang, S.F., Fu, X.W., Shang, L.H., 2009. Mercury distribution and speciation in water and fish from abandoned Hg mines in Wanshan, Guizhou province China. Sci. Total Environ. 407 (18), 5162-5168.

Rodrigues, A.C.M., Jesus, F.T., Fernandes, M.A.F., Morgado, F., Soares, A.M.V.M., Abreu, S.N., 2013. Mercury toxicity to freshwater organisms: extrapolation using species sensitivity distribution. Bull. Environ. Contam. Toxicol. 91 (2), 191-196.

Schuler, L.J., Hoang, T.C., Rand, G.M., 2008. Aquatic risk assessment of copper in freshwater and saltwater ecosystems of South Florida. Ecotoxicology 17 (7), 642-659.

Shao, D.D., Wu, S.C., Liang, P., Kang, Y., Fu, W.J., Zhao, K.L., et al., 2012. A human health risk assessment of mercury species in soil and food around compact fluorescent lamp factories in Zhejiang Province, PR China. J. Hazard. Mater. 221-222, 28-34.

Sveinsdottir, A.Y., Mason, R.P., 2005. Factors controlling mercury and methylmercury concentrations in Largemouth Bass (Micropterus salmoides) and other fish from Maryland reservoirs. Arch. Environ. Contam. Toxicol. 49, 528-545.

Taylor, J.K., 2000. Mercury reduction efforts in Michigan. Fuel Process. Technol. 65, 69-77.

Taylor, H., Appleton, J.D., Lister, R., Smith, B., Chitamweba, D., Mkumbo, O., et al., 2005. Environmental assessment of mercury contamination from the Rwamagasa artisanal gold mining centre, Geita District Tanzania. Sci. Total Environ. 343 (1-3), 111-133.

Van Straalen, N.M., Van Rijn, J.P., 1998. Ecotoxicological risk assessment of soil fauna recovery from pesticide application. Rev. Environ. Contam. Toxicol. 154, 83-141.

Wagner, C., Lokke, H., 1991. Estimation of ecotoxicological protection levels from NOEC toxicity data. Water Res. 25 (10), 1237-1242.

Wang, N., Zhu, Y.M., Piao, M.Y., Meng, D., 2005. Chemical ecology effect of mercury pollution on upper Songhua River Areas. Sci. Geogr. Sin. 25 (6), 737-741.

Wu, F.C., Feng, C.L., Cao, Y.J., Zhang, R.Q., Li, H.X., Liao, H.Q., et al., 2011a. Toxicity characteristic of zinc to freshwater biota and its water quality criteria. Australas. J. Ecotoxicol. 6 (4), 367-382.

Wu, F.C., Meng, W., Cao, Y.J., Li, H.X., Zhang, R.Q., Feng, C.L., et al., 2011b. Derivation of aquatic life water quality criteria for cadmium in freshwater in China. Res. Environ. Sci. 24 (2), 172-184.

Wu, F.C., Meng, W., Zhang, R.Q., Li, H.X., Cao, Y.J., Xu, B.B., et al., 2011c. Aquatic life water quality criteria for nitrobenzene in freshwater. Res. Environ. Sci. 24 (1), 1-10.

Zahir, F., Rizwi, S.J., Haq, S.K., Khan, R.H., 2005. Low dose mercury toxicity and human health. Environ. Toxicol. Pharmacol. 20 (2), 351-360.

Zhang, R.Q., Wu, F.C., Li, H.X., Feng, C.L., Guo, G.H., 2012. Deriving aquatic water quality criteria for inorganic mercury in China by species sensitivity distributions. Acta Sci. Circumst. 32 (2), 440-449.

Zhao, J.L., Ying, G.G., Liu, Y.S., Chen, F., Yang, J.F., Wang, L., 2010. Occurrence and risks of triclosan and triclocarban in the Pearl River system, South China: from source to the receiving environment. J. Hazard. Mater. 179 (1-3), 215-222. 